\title{
Peripheral Cemento-ossifying Fibroma
}

\author{
Dr. Khushbu Adhikari, ${ }^{1}$ Dr. Anita Shah ${ }^{2}$ \\ ${ }^{1}$ Department of Periodontology and Oral Implantology, College of Dental Surgery, \\ Universal College of Medical Sciences, Bhairahawa, Nepal, \\ ${ }^{2}$ Department of Pathology, Universal College of Medical Sciences, Bhairahawa, Nepal.
}

\begin{abstract}
Localised gingival overgrowth is commonly encountered in our practice. They can be histologically different such as the peripheral giant cell granuloma, giant cell fibroma, pyogenic granuloma or fibroma. A diagnosis based only on the clinical feature is difficult to make because of their similarity in clinical presentation with other gingival overgrowths. Therefore, histopathological examination is mandatory for making an accurate diagnosis that will ultimately help us to treat the underlying disease. This is a case report of Peripheral cemento-ossifying fibroma, which is a slow progressing and asymptomatic gingival growth until it causes noticeable deformity.

Keywords: Cemento-ossifying fibroma; gingival overgrowth; histopathology.
\end{abstract}

\section{INTRODUCTION}

Various differential diagnosis of the gingival overgrowth are fibroma, pyogenic granuloma, giant cell fibroma. Only $8 \%$ of the oral tumours occurs on the gingiva, of which $9.3 \%$ are diagnosed as fibromas. ${ }^{1} \quad$ Peripheral cemento-ossifying fibroma (PCOF) accounts for 3.1\% of all oral tumours and 9.6\% of gingival lesions. ${ }^{2}$ They are slow growing spherical tumour and local factors are suggested to influence the development of the lesion. ${ }^{3}$ They clinically resemble pyogenic granuloma and other entities. Hence, radiographic and histopathological examination are essential for an accurate diagnosis. Cementoossifying fibroma is considered a rare osteogenic tumour (non-ododntogenic) with variable expressiveness. Long term post-operative follow-up is extremely important because of a relatively high recurrence rate of approximately $20 \%{ }^{4}$ This article reports a case of PCOF, which was treated by surgical excision with no recurrence for a period of one year.

\section{CASE REPORT}

A 12-year-old female patient reported to the Department of Periodontology and Oral Implantology, College of Dental Surgery, Universal College of Medical Sciences, Bhairahawa, Nepal with a chief complaint of increased spacing between the upper front tooth region of the jaw for one year.

\footnotetext{
Correspondence:

Dr. Khushbu Adhikari

Department of Periodontology and Oral Implantology,

College of Dental Surgery, Universal College of Medical Sciences,

Bhairahawa, Nepal.

email: adhkhush@gmail.com

Citation

Adhikari K, Shah A. Peripheral cemento-ossifying fibroma. J Nepal Soc Perio Oral Implantol. 2017;1(2):75-7
}

Intra-oral examination revealed a solitary, $1 \mathrm{X} \quad 1 \mathrm{~cm}$ gingival growth, with pinkish lobulated surface and mildly erythematous margins on the labial gingiva of teeth 11 and 21 (Figure 1). Pathologic migration of teeth 11 and 21 was present which could be due to the pressure from the growth, as no trauma from occlusion or any family history of diastema could be elicited. On palpation, it was sessile, firm and non-tender. The borders of the growth could be easily delineated from the underlying tissue with the help of an explorer. Plaque and calculus was present but bleeding was not present. Grade I mobility was noticed in relation to teeth 11 and 21. Lymph nodes were not palpable. A mild gingival inflammation could be noticed in relation to the marginal gingiva of lower anteriors with presence of plaque.

Electric pulp testing, intra-oral periapical radiograph, a complete blood investigation and an excisional biopsy was planned under local anaesthesia. The intra-oral periapical radiograph revealed a radiolucency along the interdental crestal bone between teeth 11 and 21 and loss of lamina dura with respect to mesial of the tooth 21 was evident (Figure 2). Correlating the history and clinical features, a provisional diagnosis of peripheral ossifying fibroma was made with pyogenic granuloma as a differential diagnosis. The guardian of the patient signed a written informed consent for the

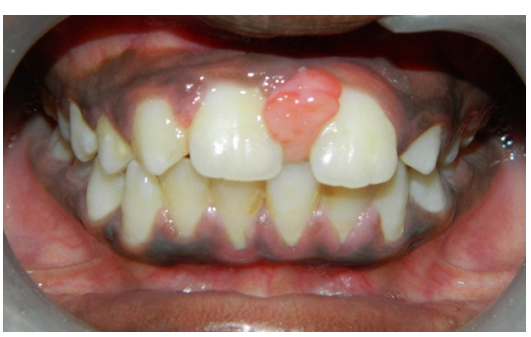

Figure 1: Preoperative photo showing gingival overgrowth.

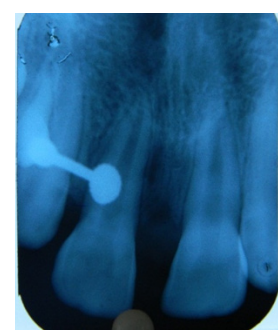

Figure 2: Intraoral periapical radiograph. 


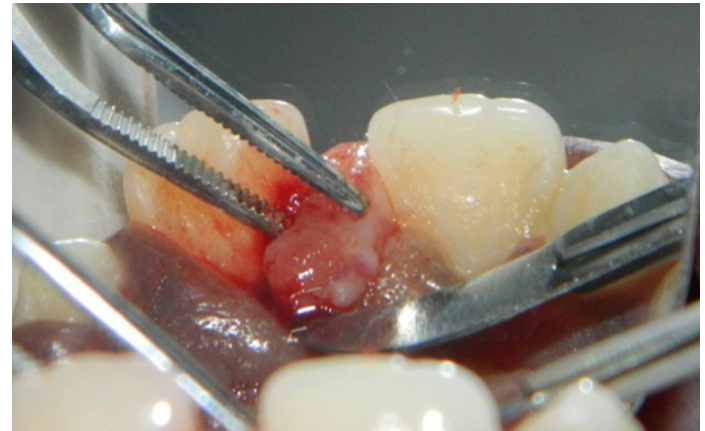

Figure 3: Excision of the growth.

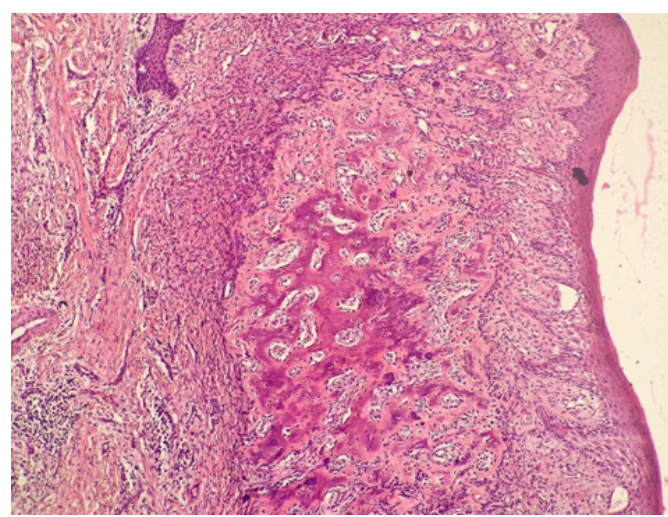

Figure 5a: Non-keratinised stratified squamous epithelium with calcification(10X).

procedure to be done and for the photographs to be kept as a record or for publication in the future.

Oral prophylaxis was performed and oral hygiene instructions were given and patient was recalled after a week for biopsy. After the application of nasopalatine nerve block palatally in between 11 and 21 an infiltration was given on the vestibule on the facial aspect of the teeth 11 and 21 . The enlargement was held with the help of a tissue forceps so as to visualize the base and external bevel incision was placed at the base of the growth in between teeth 11 and 21 palatally upto the bone (Figure 3). The excised tissue was fixed in a $10 \%$ formalin solution and was sent for histopathological examination (Figure 4). The histopathology report explained it as non-keratinised stratified squamous epithelium with focal ulcerations present. The underlying stroma was highly

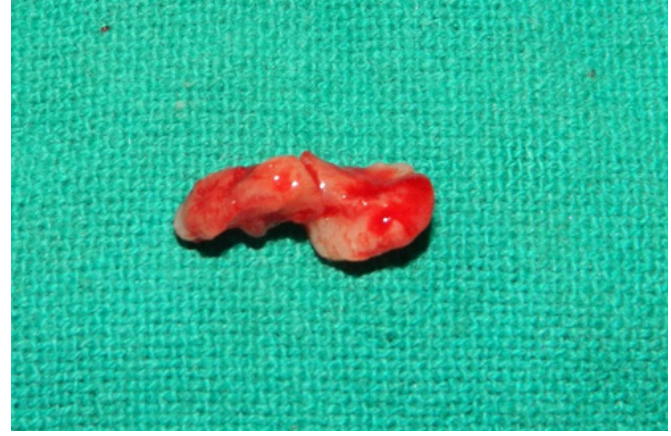

Figure 4: Excised tissue for biopsy.

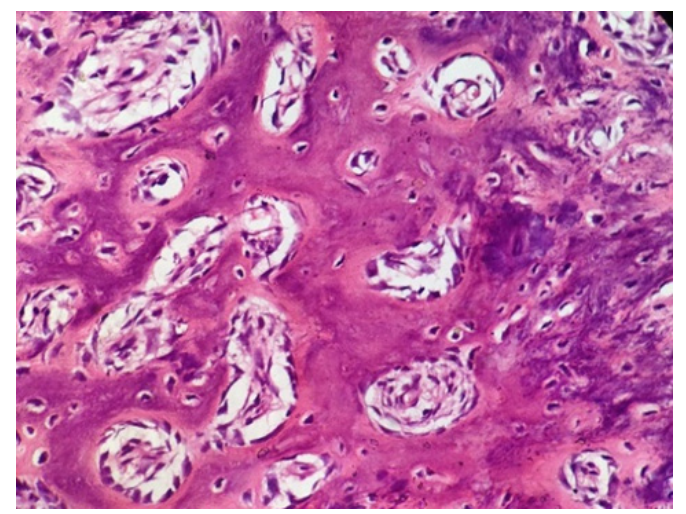

Figure 5b: Ossification with osteoblastic rimming seen

(40X).

cellular with fibrous tissue, ossification with osteoblastic rimming was seen. Few inflammatory cells and areas of calcification was also seen (Figure 5a, 5b).Thus, a final diagnosis of cemento-ossifying fibroma of the gingiva was made.

The site was then pressed with a moistened gauze piece for about five minutes so that bleeding could be controlled. Once the bleeding was stopped a periodontal dressing was placed and post-operative instructions were given. The patient was recalled after 7 days for removal of the pack. On the 7 th day, the healing was satisfactory. The patient was reinforced with the oral hygiene instructions and advised for an orthodontic consultation for the diastema closure with regular follow-up. No recurrence was noted upto one year of follow-up period (Figure 6).

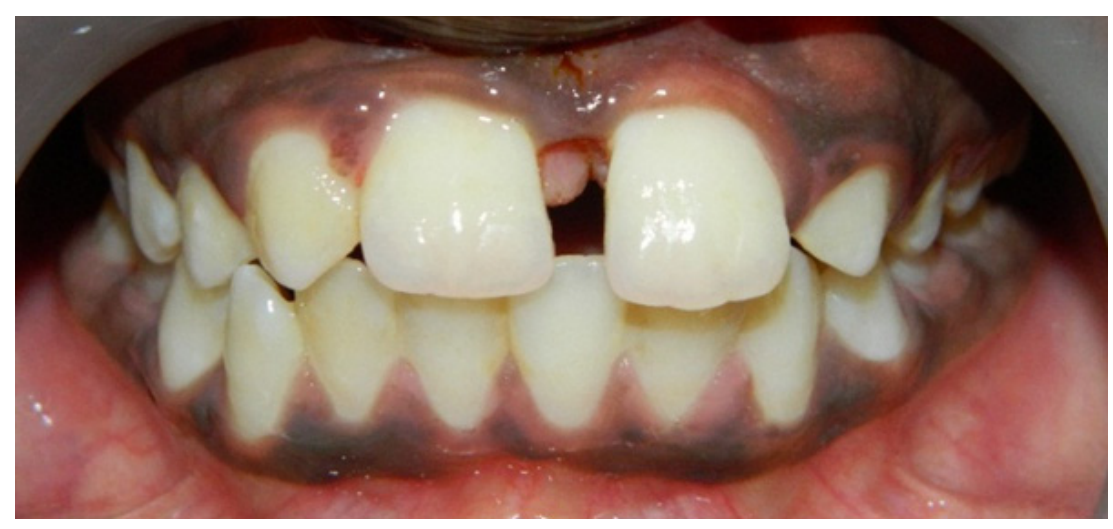

Figure 6: Follow-up at 12 months. 


\section{DISCUSSION}

Peripheral cemento-ossifying fibroma consists of fibrous tissue with variable amounts of calcific material resembling bone, cementum or both. Gingival lesions are rare compared with lesions that appear within bone.5 Although aetiopathogenesis of PCOF is still unclear, it has been suggested that these lesions originate from cells of periodontal ligament.6 It is predominantly seen in women and often associated with local irritants such as subgingival plaque, calculus or trauma from dental appliances.2,3 Hormonal influence has been suggested to play a role in PCOF with peak incidence between second and third decades of life.7 About $60 \%$ of PCOF occur in maxilla, commonly involving the anterior gingiva. Clinically, it appears as a slow growing gingival mass measuring less than $2 \mathrm{~cm}$ in size and more commonly involving the interdental gingiva.8,9 It may be sessile or pedunculated, similar in colour to that of the adjacent gingiva or slightly reddish, and may have ulcerated surface. PCOF is more firm and less friable than other lesions and generally has a longer course, which explains calcification or ossification.6

Radiographs usually do not reveal any underlying bone involvement but rarely superficial erosion of bone may be seen.10 Some lesions may show foci of calcifications scattered in the central area of the lesion in radiographs. Therefore, histological examination is imperative for definitive diagnosis, which is based on focal presence of bone or other calcifications in cellular connective tissue.4 Management of PCOF consists of removal of aetiological factors, scaling and aggressive surgical excision. Some authors have suggested excision of involved periodontal ligament and periosteum to avoid recurrence of incompletely removed lesions.10 PCOF has high recurrence rate of approximately 20\%, hence long term follow-up is imperative. Most of the above mentioned clinical and histopathological features of PCOF correlated with our case. The lesion was successfully treated, and the patient was followed up for a period of one year with no recurrence noted.

Correlating clinical features of gingival overgrowth with the histopathological examination helps us to make the correct diagnosis and treat the underlying disease. PCOF is a slowprogressing, asymptomatic and non-neoplastic lesion which may progress and persist for long periods until patients seek treatment. Postoperative follow-up is a must because of high recurrence rate.

\section{REFERENCES}

1. Zackheim HS, Pinkus H. Perifollicular Fibromas. Arch Dermatol. 1960; 82: 913-7.

2. Kenney JN, Kaugars GE, Abbey LM. Comparison between the peripheral ossifying fibroma and peripheral odontogenic fibroma. J Oral Maxillofac Surg. 1989 Apr;47 (4):378-82

3. Batsakis JG. Non-odontogenic tumours: clinical evaluation and pathology. In: Thawley SE, Panje WR, Batsakis JG, Lindberg RD, editors. Comprehensive management of head and neck tumours. 2nd ed. Philadelphia: WB Saunders Co; 1999.p.1641-2.

4. Cuisia ZE, Brannon RB. Peripheral ossifying fibroma-a clinical evaluation of 134 pediatric cases. Pediatr Dent. 2001 May-Jun; 23(3):2458.

5. Endo Y, Uzawa K, Mochida Y, Nakatsuru M, Shiiba M, Yokoe H, et al. Differential distribution of glycosaminoglycans in human cementifying fibroma and fibro-osseous lesions. Oral Dis. 2003 Mar; 9(2):73-6.

6. Neville BW, Damm DD, Allen CM, Bouquot JE. In: Text book of oral and maxillofacial pathology.2nd ed. Philadelphia: WB Saunders Co;2004.p.451-2.

7. Marx RE, Stern D. In: Oral and maxillofacial pathology: a rational for diagnosis and treatment. Chicago: Quintessence; 2003. p.23-5.

8. Bhaskar SN, Levin MP. Histopathology of the human gingiva (study based on 1269 biopsies). J Periodontol. 1973 Jan; 44 (1):3-17.

9. Eversole LR, Leider AS, Nelson K. Ossifying fibroma: a clinicopathologic study of sixty-four cases. Oral Surg Med Oral Pathol. 1985 Nov; 60(5):505-11.

10. Kendrick F, Waggoner WF. Managing a peripheral ossifying fibroma. ASDC J Dent Child. 1996 Mar-Apr; 63(2):135-8. 